\title{
A European Union Price Policy Model for Southern Spain ${ }^{+}$
}

\section{Carmen Lima and M. Alejandro Cardenete*}

\begin{abstract}
Social Accounting Matrices (SAM) are databases that focus on the intersectoral relationships in a given economy that close the circular flow of income. This article deals with the European Regional Development Fund (ERDF) in Andalusia, a Spanish region that European regional policy classifies in Objective 1. We apply the Leontief model to selected SAMs for the years 1990, 1995, and 1999, in order to develop a price model for assessing the impact of this funding on aggregate and sectoral prices.
\end{abstract}

Keywords: Social Accounting Matrix, Regional Accounting, Structural Analysis.

JEL Classifications: C67, D57, R15

\section{INTRODUCTION}

Social Accounting Matrices (SAM) are expanded input-output tables that can include, for example, data from household budget surveys and other national or regional accounting sources. They can be a useful tool for impact analyses of certain exogenous shocks, since they combine various arrays to focus on a single analysis. Such is the case of the present work, which evaluates the effects on prices of a European regional policy in the region of Andalusia.

The European Regional Development Fund (ERDF) is a European Structural Fund that supports the use of physical capital to promote regional development. The fund is a critical element within the Community Support Framework (CSF) through which the national government and the European Commission establish priority axes and financial endowments for the economic and social development of poorer regions or countries within the EU. The first, second, and third CSFs covered the periods 1989-1993, 1994-1999 and 2000-2006, respectively, and a new one has recently been approved for 2007-2013.

Our goal here is to conduct an impact analysis of the ERDF for two different scenarios: the current one, in which these funds continue to have an impact on Andalusian final demand, and a hypothetical one in which they no longer represent a source of regional income for the region. Specifically, we conduct a counterfactual analysis, applying the Leontief theory to three different databases (selected SAMs for the years 1990, 1995, and 1999) in order to study how output and prices would change with the removal of these funds. Each of the three databases is used to assess the CSF for a given year.

\footnotetext{
${ }^{+}$Both authors thank the Andalusian regional government for funding this study through the Excellence Research Project SEJ01252 and the Project SEJ-246. We also thank the Catalonian regional government for the XT0039-2004 Research Project. M. Alejandro Cardenete thanks the Fundación Centro de Estudios Andaluces (centrA), the Spanish Ministry of Science and Technology (SEC2003-05112/ECO) and the General Secretariat of Economy of the Andalusian Regional Government. The authors are also grateful to Dr. Ferran Sancho for his helpful comments and assume full responsibility for any errors in this paper.

* M. Carmen Lima Díaz is Assistant Professor and M. Alejandro Cardenete Flores is Associate Professor at the Department of Economics, Universidad Pablo de Olavide.

Contact author: M. Carmen Lima Díaz, Department of Economics, Universidad Pablo de Olavide, Carretera de Utrera km 1, 41013 Sevilla, SPAIN. E-mail: mlimdia@upo.es.

(C) Southern Regional Science Association 2010.

ISSN 1553-0892

SRSA, 1601 University Avenue, PO Box 6025, Morgantown, West Virginia 26506-6025, USA.
} 


\section{TABLE 1: Annual Funds Received by Andalusia and Its Regional GDP} (millions of pesetas)

\begin{tabular}{lrrr}
\hline \hline & 1990 & 1995 & 1999 \\
\hline ERDF & 55,294 & 81,499 & 145,779 \\
Regional GDP & $6,254,242$ & $9,215,035$ & $12,048,341$ \\
Percentage over GDP & 0.88 & 0.88 & 1.21 \\
\hline \hline
\end{tabular}

Source: Own elaboration based on Spanish Ministry of Economy and Andalusian Regional Government.

Hence, the overall goal of this analysis is to present a price model that can be used to assess how prices in Andalusia respond to the ERDF. Andalusia is an "Objective 1 region," meaning that the GDP per capita is less than 75 percent of the Community average for the study period. ERDF funding is an important source of the region's income, contributing to its overall GDP (see Table 1). The Fund weighs heavily in the Andalusian economy. Hence, as the ERDF is diverted increasingly to countries that joined the European Union during its fifth and sixth enlargements, the analysis presented here will appear ever more pertinent to Andalusia.

We focus on demand-side effects (as studied by Sharify and Batey (2006), among others), since ERDF investments tend to concentrate on basic infrastructure. Our assumption is that these funds provide a positive Keynesian shock to the economy by increasing public expenditure and encouraging growth in savings and investment and foreign sector accounts. The counterfactual, in this case, therefore assesses the potential fall in aggregate demand caused by the loss of these funds to Andalusia. A study that focuses on the supply-side effects of the ERDF, including its effect on costs, productivity and competitiveness (Sosvilla, Bajo-Rubio, and DíezRoldán, 2006), would complement the results presented here. Such an analysis is a likely focus of future papers.

SAMs are elaborated input-output tables. As such they are commonly used because they are readily understood and are useful in short-run policy evaluation. Pyatt and Round (1979, 1985), Defourny and Thorbecke (1984), Pyatt (1988) and Stone (1978), among others, have contributed to the development of SAMs. The model presented here, which studies a given year in each simulation, allows us to study how prices might react to the removal of the ERDF investments. SAMs typically underlie Applied General Equilibrium Models, which are used to examine economic interrelations in an economy by assuming theoretical relationships among the factors of production for various sectors of the economy and that detail connections between an economy's final demand and its value added. Price models predicated on SAMs have been used previously to study Spanish regional economies. Llop and Manresa (2004) examined Catalonia and Cardenete and Sancho (2002) focused on fiscal issues in Andalusia.

In this study, a SAM allows us to focus on how an important source of external investment funding affects prices in Andalusia. Although the analysis could have been performed using extended input-output accounts instead of SAMs, we chose the latter in view of the larger project for which this paper is part. This umbrella study has the greater aim of developing an Applied General Equilibrium Model (AGEM) of Andalusia. AGEMs make it possible to reach a wider-ranging set of conclusions than do SAMs since they are more flexible in terms of their key assumptions, such as technology change. In particular they allow for substitution among factors of inputs and factors of production. But AGEMs are not ideal either. For example, while they may produce more accurate predictions, they do so at the price of analysts assuming specific functional relationships among inputs that may not represent the 
actual behavior of the institutions involved. Moreover, difficulties of solving rather complex mathematical optimization problems also can obtain. As we have previously asserted, we find it important to understand and work with a SAM framework before undertaking more complex analyses.

This paper is structured as follows. In the second section, we apply the Leontief model to a selected SAM in order to calculate the fall in output that would result from a change in final demand should ERDF discontinue for Andalusia. The third section presents the price model and gives our main results in terms of both aggregate and sectoral prices, and also outlines an approach to consumer welfare. We finish with some conclusions.

\section{OUTPUT DECLINE AND MULTIPLIER DECOMPOSITION IN A SOCIAL ACCOUNTING MATRIX FRAMEWORK}

Two SAMs used in this study have been compiled for the years 1990 (Cardenete, 1998) and 1995 (Cardenete and Sancho, 2003) using all possible available official data. A third, for 1999 , is an update of the 1995 SAM using the cross entropy method (CEM) (Cardenete and Sancho, 2004). That the third SAM is an update based on minimal hard data from 1999 should be recalled when simulations using it are interpreted. Unfortunately the 2000 SAM had not yet been published when this paper was written. The authors are currently constructing this SAM, which should provide better results for that year.

The three SAMs discussed above were published in pesetas. We aggregated the SAMs using sixteen accounts, defining as endogenous productive factors (accounts 11 and 12, "Labor" and "Capital," respectively), the household sector (account 13, "Consumers"), and ten industrial activities (accounts 1 through 10). The exogenous sectors were "Savings and Investment," "Government," and "International Trade Sector" accounts (14, 15, and 16, respectively),

TABLE 2: Structure of Social Accounting Matrices for Andalusia

\begin{tabular}{ll}
\hline \hline Sector \# & Sector description \\
\hline 1 & Agriculture, cattle \& forestry and fishing \\
2 & Extractives \\
3 & Electricity and natural gas \\
4 & Industrial manufacturing \\
5 & Construction \\
6 & Commerce \\
7 & Transport and communications \\
8 & Other Services \\
9 & Commercial services \\
10 & Non-commercial services \\
11 & Labor \\
12 & Capital \\
13 & Consumers \\
14 & Savings/Investment \\
15 & Government \\
16 & Foreign sector \\
\hline \hline Note: Endogenous sectors include 1 to 13: Exogenous sectors from 14 to 16.
\end{tabular}


following the example of previous studies in this area. Table 2 gives the complete disaggregation.

Following Pyatt and Round (1979), we use the accounting multipliers matrix to decompose our data into three separate effects: own, open, and circular effects. The latter, which exclude any interindustry effects, measure the impact of an exogenous unit of rent on an sector's own accounts deriving from the circular flow of rent. The open or crossed effects matrix gives the effect of a monetary unit received by a given account on the remaining accounts. Lastly, the own or internal effects matrix is comprised of several submatrices, including an identity matrix (which confirms that there are no transfers among productive factors), a second matrix that traces the transactions between institutions, and the third submatrix that includes interindustry transactions and corresponds to the Leontief inverse. To make the figures easier to interpret, we have subjected the multiplicative transformation to an additive transformation.

In short, we intend to use the multiplicative decomposition prescribed above using basic multiplier theory. Thus, we decompose Andalusian rent generation under two different scenarios: the current "true" scenario, in which EU financing contributes to final demand, and a hypothetical scenario in which the ERDF income is excluded. More specifically, we calculate the effect of the removal of these funds from final demand and, hence, total productive output. The results are presented in Tables 3, 4, and 5 .

Specifically, after formulating the Leontief model, we apply it to our SAM and get the so-called Accounting Multipliers Matrix (Ma). An element $m a_{i j}$ shows the effect that an exogenous income unit of endogenous account $j$ has on the income of endogenous account $i$. In effect, it shows how much monetary income is generated in sector $i$ as a result of the circular flow of income when sector $j$ receives a unitary shock. If we sum up these values by columns, we get the total effect caused by an exogenous shock received by one account on the remaining economic activity:

Consider the case when an exogenous account experiences an adverse shock, such as that caused by the removal of ERDF funding from the Andalusian economy. Equation (1) shows that a change in final demand necessarily causes a change in total output, $\Delta \mathrm{x}^{1}$. The removal of the European funds from the Andalusian economy can thus be simulated by decreasing final demand, $\Delta \mathbf{y}$, for the funds in a set of SAM accounts.

$$
\Delta \mathbf{x}=\mathbf{M a} \cdot \Delta \mathbf{y}
$$

The Community Support Frameworks (CSFs) are multi-year initiatives that promote the economic development of a region by defining financial priorities and shaping strategic plans for enacting EU regional policy. This paper analyzes the CSFs for the periods 1989-1993, 19941999, and 2000-2006. We perform three simulations, in which each of our chosen matrices (SAM-1990, SAM-1995 and SAM-1999) aids our study of a single CSF.

To discern how the ERDF affects Andalusian regional output, we need specific information about the allocation of these funds among the various activity sectors. The Appendix presents the allocation rules that we have followed, which are based upon those of Lima and Cardenete (2005). The Appendix also shows the annual funds granted for the years 1990, 1995,

\footnotetext{
${ }^{1}$ For further information about the Leontief model, see Pulido and Fontela (1993).
} 
and 1999. These rules cite a number of financial priority dimensions (basic infrastructure, industry, craftsmanship and services to firms, tourism, agriculture, human resources and technical help) approved by the European Commission and the national or regional government. The funding assigned to each dimension is shared out across the ten activity accounts of the corresponding SAM, in accordance with the needs of the specific projects it will finance.

The following tables give the results of the simulation in which the ERDF are dropped from the Andalusian economy. As Table 1 shows, this financing is worth 55.294, 81.499 and 145.779 million pesetas, respectively, figures that result from annualizing CSF for each reference year. (Consejería de Economía y Hacienda, 1994, 2000; Ministerio de Economía y Hacienda, 1995).

The first two columns of Table 3, which present the pre-simulation figures for 1990, show the final demand (FD) and sectoral output (SO) of the ten activity sectors. If we reduce the final demand corresponding to the ERDF funds sector by sector, we get the new vector FD.

A decline in the ERDF available to Andalusia would cause the state's final demand to fall by nearly 4 percent in Construction (5), 1.3 percent in Trade (6) and 1.1 percent in Other Services (8). More than 70 percent of the annualized ERDF budget is used to finance infrastructure to enhance regional integration and to target and promote economic developments. The remaining funds go to Manufacturing and Agriculture, although a small amount also is allocated to Human Resources (see Table A.1 in Appendix). With regard to output behavior, it is clear from the table that some sectors that did not initially receive an adverse shock show symptoms of decreasing value as the result of the circular flow of income. These include the Mining (2), Electricity and Natural Gas (3), Transport and Communications (7), and Trade (9). Manufacturing (4) and Agriculture and Forestry (1) show elastic behavior when final demand changes; that is, they fluctuate widely in response to the direct and indirect effects of the initial demand. In Andalusia, these two sectors receive the most funding from the European Union. In aggregate terms, in 1990 ERDF monies represented 1.2 percent of Andalusian final demand and 1.1 percent of the region's total output.

We repeat the simulation for 1995, and list the results in Table 4. Here again, the lion's share of the funds can be found in Construction (5) and in some service sectors, such as those relating to Trade (6), Other Services (8), and Non-commercial services (10). A large share (65 percent) of the annualized budget is again allocated to infrastructure for regional integration and for marketing efforts and infrastructure needed to promote economic activity. Another 20 percent goes to services. By contrast, the amount of funding invested in Human Resources increases by 400 percent (see Table A.2 in the Appendix). As in 1990, the circular flow of income causes the output vector to change, even though not all sectors experience an exogenous shock to their final demand. In this case, output for four sectors (Mining (2), Electricity and Natural Gas (3), Transport and Communication (7), and Trade (9) falls by nearly 1 percent following the loss of the funds. As in 1990, Manufacturing (4) registers a high elasticity of output in relation to changes in final demand. The Construction (5) and Non-commercial Services (10) sectors decline by about 1 percent. As we can see, the activity sectors for 1990 and 1995 display a similar pattern. During the latter period, both final demand and total output experience an aggregate fall of about 1 percent, with the former approximating the aggregate fall for 1990 .

As Table 5 shows, in 1999 much of the European Commission funding went to Electricity and Natural Gas (3), Trade (6), and Other Services (8). As the funding needs of basic 
infrastructure sectors had been addressed in previous years, most of the funds in question were invested in Trade (31 percent), Other Services (25 percent), and Non-commercial Services (24 percent) (see Table A.3 in the Appendix). Sectors showing an output elasticity in relation to changes in final demand that exceed one percent include the Agriculture, Cattle and Forestry (1) and Manufacturing Industry (4) sectors, in line with previous years. Despite not having received any initial support from the ERDF, the Transports and Communications (7), Commercial Services (9), Non-Commercial Services (10), and even Mining (2) sectors react to the finaldemand disturbance. In aggregate terms, a 1 percent fall in final demand and a 1.2 percent fall in total output registered for this year.

TABLE 3: Simulated Declines in Final Demand (FD) and Sectoral Output (SO) for 1990 (in millions of pesetas, unless otherwise noted)

\begin{tabular}{|c|c|c|c|c|c|c|}
\hline \multirow{2}{*}{ Productive Sectors } & \multicolumn{2}{|c|}{ With Funds } & \multicolumn{4}{|c|}{ Funds Removed } \\
\hline & FD & $\mathrm{SO}$ & FD' $^{\prime}$ & $\mathrm{SO}^{\prime}$ & FD $\% \Delta$ & $\mathrm{SO} \% \Delta$ \\
\hline 1 Agriculture, cattle \& forestry & 280,553 & $1,038,670$ & 278,882 & $1,030,343$ & -0.6 & -0.8 \\
\hline 2 Extractives & 258,160 & 883,368 & 258,160 & 877,823 & 0.0 & -0.6 \\
\hline 3 Electricity and natural gas & 16,683 & 386,396 & 16,683 & 383,010 & 0.0 & -0.9 \\
\hline 4 Manufacturing industry & $1,773,252$ & $5,528,349$ & $1,769,930$ & $5,483,585$ & -0.2 & -0.8 \\
\hline 5 Construction & $1,048,600$ & $1,268,003$ & $1,007,684$ & $1,225,025$ & -3.9 & -3.4 \\
\hline 6 Commerce & 130,331 & $2,214,215$ & 128,671 & $2,191,691$ & -1.3 & -1.0 \\
\hline 7 Transport and Communications & 32,429 & 978,470 & 32,429 & 968,333 & 0.0 & -1.0 \\
\hline 8 Other services & 646,861 & $1,979,708$ & 639,983 & $1,959,000$ & -1.1 & -1.0 \\
\hline 9 Commercial Services & 0 & 606,234 & 0 & 600,331 & 0.0 & -1.0 \\
\hline 10 Non-commercial services & 346,956 & 351,192 & 346,110 & 350,309 & -0.2 & -0.3 \\
\hline Total Decline & $4,533,825$ & $15,234,605$ & $4,478,531$ & $15,069,449$ & -1.2 & -1.1 \\
\hline
\end{tabular}

Note: Sum of own, open, and circular effects derived from the multiplier decomposition.

TABLE 4: Simulated Declines in Final Demand (FD) and Sectoral Output (SO) for 1995 (in millions of pesetas, unless otherwise noted)

\begin{tabular}{lrr|rrrr}
\hline \multirow{2}{*}{\multicolumn{1}{c}{ Productive Sectors }} & \multicolumn{2}{c|}{ With Funds } & \multicolumn{4}{c}{ Funds Removed } \\
\cline { 2 - 7 } & \multicolumn{1}{c|}{ FD } & \multicolumn{1}{c}{ SO } & \multicolumn{1}{c}{ FD' } & \multicolumn{1}{c}{ SO' } & FD \% $\Delta$ & SO \% $\Delta$ \\
\hline 1 Agriculture, cattle \& forestry & 491,672 & $1,434,885$ & 491,597 & $1,428,005$ & 0.0 & -0.5 \\
2 Extractives & 28,653 & 468,086 & 28,653 & 464,088 & 0.0 & -0.9 \\
3 Electricity and natural gas & 465 & 542,310 & 465 & 537,432 & 0.0 & -0.9 \\
4 Manufacturing industry & $2,987,917$ & $7,792,697$ & $2,985,264$ & $7,736,022$ & -0.1 & -0.7 \\
5 Construction & $1,521,043$ & $2,025,719$ & $1,467,334$ & $1,959,079$ & -3.5 & -3.3 \\
6 Commerce & 357,468 & $3,419,619$ & 353,056 & $3,388,633$ & -1.2 & -0.9 \\
7 Transport and Communications & 235,913 & $1,259,954$ & 235,913 & $1,249,898$ & 0.0 & -0.8 \\
8 Other services & $1,148,408$ & $2,873,148$ & $1,132,230$ & $2,839,639$ & -1.4 & -1.2 \\
9 Commercial Services & 37,610 & $1,196,951$ & 37,610 & $1,186,657$ & 0.0 & -0.9 \\
10 Non-commercial services & 779,736 & 816,062 & 775,262 & 811,305 & -0.6 & -0.6 \\
Total Decline & 491,672 & $1,434,885$ & 491,597 & $1,428,005$ & 0.0 & -0.5 \\
\hline \hline
\end{tabular}

Note: Sum of own, open, and circular effects derived from the multiplier decomposition. 
TABLE 5: Simulated Declines in Final Demand (FD) and Sectoral Output (SO) for 1999 (in millions of pesetas, unless otherwise noted)

\begin{tabular}{lrr|rrrr}
\hline \multirow{2}{*}{\multicolumn{1}{c}{ Productive Sectors }} & \multicolumn{2}{c}{ With Funds } & \multicolumn{4}{c}{ Funds Removed } \\
\cline { 2 - 7 } & \multicolumn{1}{c}{ FD } & \multicolumn{1}{c}{ SO } & \multicolumn{1}{c}{ FD' } & \multicolumn{1}{c}{ SO' } & FD \% $\Delta$ & SO \% $\Delta$ \\
\hline 1 Agriculture, cattle \& forestry & 936,362 & $1,300,079$ & 928,440 & $1,287,624$ & -0.8 & -1.0 \\
2 Extractives & 27,697 & 115,324 & 27,697 & 114,433 & 0.0 & -0.8 \\
3 Electricity and natural gas & 1,120 & 484,517 & 970 & 477,368 & -13.4 & -1.5 \\
4 Manufacturing industry & $3,209,741$ & $4,999,769$ & $3,199,914$ & $4,969,198$ & -0.3 & -0.6 \\
5 Construction & $2,499,019$ & $2,865,800$ & $2,490,055$ & $2,854,535$ & -0.4 & -0.4 \\
6 Commerce & 551,858 & $3,339,925$ & 506,614 & $3,255,514$ & -8.2 & -2.5 \\
7 Transport and Communications & 471,605 & $1,300,845$ & 471,605 & $1,289,540$ & 0.0 & -0.9 \\
8 Other services & $1,573,621$ & $4,051,016$ & $1,535,003$ & $3,976,758$ & -2.5 & -1.8 \\
9 Commercial Services & 39,746 & $1,923,902$ & 39,746 & $1,897,159$ & 0.0 & -1.4 \\
10 Non-commercial services & $1,309,418$ & $1,455,938$ & $1,309,418$ & $1,454,071$ & 0.0 & -0.1 \\
Total Decline & $10,620,187$ & $21,837,114$ & $10,509,461$ & $21,576,202$ & -1.0 & -1.2 \\
\hline \hline
\end{tabular}

Note: Sum of own, open, and circular effects derived from the multiplier decomposition.

\section{PRICE FORMATION}

Given the production structure of the economy, production prices behave according to standard average cost rule:

$$
\begin{aligned}
& p_{j}=\left(\sum_{i=1}^{10} p_{i} \cdot a_{i j}+w \cdot l_{j}+r \cdot k_{j}+r w p \cdot m_{j}\right), \\
& q_{j}=p_{j}\left(1+t_{j}\right) .
\end{aligned}
$$

The notation for equations ( $2 a)$ and $(2 b)$ is as follows:

$p_{j}$ : composite producer price of sector $j$ 's output without indirect taxes.

$a_{i, j}$ : input-output technical coefficients.

$w$ : wage rate.

$l_{j}$ : labor technical coefficients of $\operatorname{sector} j$.

$r$ : capital services rate.

$k_{j}$ : capital technical coefficients of sector $j$.

rwp : rest of the world price index.

$m_{j}:$ technical coefficients for foreign $\operatorname{good} j$.

$q_{j}$ : final price of sector $j$.

$t_{j}:$ ad valorem tax rate on production of sector $j$.

Wages initially behave as a numeraire and only change after simulation. When calculating the technical coefficients $a_{i, j}, l_{j}, k_{j}$, and $m_{j}$; we use the information in the three SAMs, as follows:

(3) $a_{i, j}=\operatorname{SAM}(i, j) / x_{j}$; 
(4) $l_{j,}=S A M(l a b o r, j) / x_{j}$;

(5) $k_{j}=S A M($ capital, $j) / x_{j}$,

(6) $m j=S A M($ foreign sector, $j) / x_{j}$.

Indirect taxation is treated via effective tax rates using data from the SAM (see Table 2):

(7) $t_{j}=S A M($ government,$j) /\left(x_{j}-S A M(\right.$ government,$j)$ ).

Production prices or unitary costs, as well as final prices and wages, are endogenous here. We also work with a consumer price index (cpi), using a basket of goods defined as follows:

(8) $c p i=\left(\sum_{i=0}^{10} p_{i} \cdot S A M(i\right.$, consumers $\left.)\right) / \sum_{j=1}^{10} S A M(j$, consumers $)$.

We consider capital and goods to be exogenous and fixed at unitary levels.

If we want to determine the effect of a price change in such a way that we allow income to change but keep utility at a fixed rate, we must use a Hicksian demand function in order to obtain the Compensating Variation. Compensating Variation calculates the change of income needed to compensate an individual after a price change in terms of utility. Since the SAMs do not address utility functions for consumers, we can approximate the influence of the funds on the individual welfare of a representative consumer by studying expenditure change $\Delta e$ in the cost of a typical basket of consumption goods:

$$
\Delta e=\left(\mathbf{q}-\mathbf{q}^{\prime}\right) \mathbf{c},
$$

where row vectors $\mathbf{q}$ and $\mathbf{q}^{\prime}$ are the final prices before and after simulation and $\mathbf{c}$ denotes the column vector of a typical basket of consumption goods. A positive or negative result indicates an increase or decrease in the consumer's welfare, respectively. By means of an algebraic manipulation, $\mathbf{q}^{\prime} \mathbf{c}^{\prime}-\mathbf{q} \mathbf{c}=\mathbf{0}$, we achieve an approximation of the Compensating Variation or more precisely a welfare measure that we call Pseudo-Compensating Variation:

$$
\begin{aligned}
C V & =\mathbf{q}^{\prime}\left(\mathbf{c}^{\prime}-\mathbf{c}\right)=\mathbf{q}^{\prime}\left(\mathbf{c}^{\prime}-\mathbf{c}\right)+\mathbf{q} \mathbf{c}-\mathbf{q} \mathbf{c} \\
& =\left(\mathbf{q}-\mathbf{q}^{\prime}\right) \mathbf{c}+\mathbf{q}^{\prime} \mathbf{c}^{\prime}-\mathbf{q} \mathbf{c}=\left(\mathbf{q}-\mathbf{q}^{\prime}\right) \mathbf{c}=\Delta e .
\end{aligned}
$$

\subsection{Price effects of the ERDF on the Andalusian economy}

Once we get the new vector of total output $\mathbf{x}$ we recalculate prices, Equations ( $2 \mathrm{a}$ and $2 \mathrm{~b}$ ), with the new coefficients from Equations (3) to (8). Now we can compare the initial and final prices $\mathbf{q}$ and $\mathbf{q}^{\prime}$. The following tables present the changes in sectoral output and final prices caused by the removal of the ERDF funds from the Andalusian economy.

Table 6 shows the sectoral prices following the drop in output, assuming that taxes remain constant. For comparative purposes, sectoral prices were initially assigned a fixed unitary value; thus, all figures of more than one show a price increase and all figures of less than one show a price drop. For the first year, prices increased in four sectors: Mining (2), Electricity and Natural Gas (3), Manufacturing (4), and Construction (5), with the most significant increase 
taking place in Construction. By contrast, some services registered a significant drop in prices. Such was the case for Other Services (8), which experienced a price decline of nearly 4 percent, as well as the Non-commercial Services sector (10), for which the decline was 6 percent.

In 1995, sectors (2), (3), (4), and (5) behaved much as they did in 1990, showing a moderate price increase, while prices fell slightly in all of the services accounts. Again, this drop was a bit more significant in sectors (8) and (10). A similar pattern can be observed for the 1999 prices. For that year, prices increased moderately in the secondary sectors but fell in Construction (5) and services accounts, undoubtedly as a consequence of the decreasing CSF investment in these areas.

Table 7 shows how the removal of ERDF funding affects the consumer price index. The simulation shows a reduction of nearly 1 percent for each of the three years, with the fall being especially marked in 1990. With regard to wages, the figures call into evidence a decline in wages that intensified during the third study year. The Compensating Variation has a negative sign, as dictated by the Leontief framework, which indicates a welfare loss in nominal terms when funds are removed.

\section{CONCLUSIONS}

This work has performed a counterfactual analysis designed to evaluate the impact of the ERDF on sectoral output and prices for the region of Andalusia. More specifically, we applied a Leontief model to selected SAM databases in an effort to determine which sectors would be most affected by the elimination of European funding from this region and to gauge the latter's degree of dependence on these funds.

TABLE 6: Simulated Relative Prices Changes by Sector for 1990, 1995, and 1999 (ratio of simulated to original prices)

\begin{tabular}{lccc}
\hline \hline \multicolumn{1}{c}{ Productive Sectors } & $\mathbf{1 9 9 0}$ & $\mathbf{1 9 9 5}$ & $\mathbf{1 9 9 9}$ \\
& & & \\
\hline 1 Agriculture, cattle \& forestry & 0.998 & 0.994 & 0.996 \\
2 Extractives & 1.004 & 1.006 & 1.004 \\
3 Electricity and natural gas & 1.001 & 1.004 & 1.007 \\
4 Manufacturing industry & 1.001 & 1.003 & 1.004 \\
5 Construction & 1.010 & 1.022 & 0.963 \\
6 Commerce & 0.990 & 0.994 & 1.003 \\
7 Transport and Communications & 0.988 & 0.994 & 0.989 \\
8 Other services & 0.961 & 0.978 & 0.962 \\
9 Commercial Services & 0.998 & 0.998 & 0.998 \\
10 Non-commercial services & 0.939 & 0.970 & 0.938 \\
\hline \hline
\end{tabular}

TABLE 7: Simulated Consumer Price Index, Wage Index, and Compensating Variation (compensating variation in millions of pesetas)

\begin{tabular}{lrrr}
\hline \hline & 1990 & 1995 & 1999 \\
\hline $\mathrm{CPI}$ & 0.993 & 0.996 & 0.991 \\
$\mathrm{~W}$ & 0.918 & 0.938 & 0.883 \\
$\mathrm{CV}$ & $-130,084$ & $-214,527$ & $-428,036$ \\
\hline \hline
\end{tabular}

Southern Regional Science Association 2010. 
In terms of output, the primary and secondary sectors reacted most strongly to the removal of the funds. This reaction can be attributed to a behavioral adjustment within certain industrial sectors - such as manufacturing, a key sector with regard to regional development - to the presence of ERDF funds. Certain sectors received large amounts of funding from the European regional policy; they include Construction (5) (1990 and 1995), Electricity and Natural Gas (3) (1999), and Trade (6) and Other Services (8) for all three years of our study.

Finally, we present a price model that allows us to analyze how prices react to the removal of these funds. A few general patterns are observed. Services accounts seem to behave better in the absence of ERDF funding, registering a slight drop in prices. But a rather significant price increase arises in remaining accounts. Thus, for 1990 and 1995, removing the EU investment in infrastructure results in average sectoral price increases ranging between one to just over two percentage points. Nevertheless, this result changes dramatically in 1999, as prices for infrastructure fall by approximately 4 percent. The competition gains captured by our simulations could compensate for the progressive elimination of the European funds, caused by the distribution of the latter among the poorer members of the recently enlarged European Union.

To conclude, we suggest that methods that focus on modeling the behavior of aidreceiving regions can make it easier to pinpoint their weaknesses and also help to detect those sectors for which the multiplying effect is broader. Furthermore, individual investment projects may be chosen as viable on the basis of whether or not they lend themselves to this type of simulation. The potential usefulness of such models to the evaluation of public policies, and as an alternative to econometric techniques, must be stressed.

\section{REFERENCES}

Cardenete, M. Alejandro. (1998) "A Social Accounting Matrix for the Andalusian Economy: 1990," Revista de Estudios Regionales, 52, 137-153.

Cardenete, M. Alejandro and Ferrán Sancho. (2002) "The Price Effects of Indirect Taxation in the Regional Economy of Andalusia," Journal of Applied Input-Output Analysis, 8, 1-13. - (2003) "Evaluación de Multiplicadores Contables en el Marco de una Matriz de Contabilidad Social Regional," Investigaciones Regionales, 2, 121-139.

. (2004) "Sensitivity of Simulation Results to Competing SAM Updates," Review of Regional Studies, 34, 37-56.

Consejería de Economía y Hacienda de la Junta de Andalucía. Dirección General de Planificación. Dirección General de Políticas Regionales FEDER. (1994) FEDER Andalucía 1989-93, Junta de Andalucía y Comisión de las Comunidades Europeas.

Consejería de Economía y Hacienda de la Junta de Andalucía. Dirección General de Fondos Europeos y Comisión Europea (2000) Programa Operativo Integrado de Andalucía (2000-2006).

Defourny, Jacques and Erik Thorbecke. (1984) "Structural Path Analysis and Multiplier Decomposition within a Social Accounting Matrix Framework," Economic Journal, 94, 111-136.

Lima, M. Carmen and M. Alejandro Cardenete. (2005) "Análisis de Impacto de los Fondos FEDER Recibidos por una Economía Regional: Un Enfoque a Través de Matrices de Contabilidad Social," Presupuesto y Gasto Público-Instituto de Estudios Fiscales, 40, $113-131$. 
Llop, María and Antonio Manresa. (2004) "Influencia de los Precios de los Factores y de las Importaciones en la Economía Catalana," Investigaciones Regionales, 4, 115-129.

Ministerio de Economía y Hacienda. Dirección General de Planificación. (1995) La planificación regional y sus instrumentos. Informe anual 1994. Madrid.

Pyatt, Graham. (1988) “A SAM Approach to Modelling," Journal of Policy Modelling, 10, 327352.

Pyatt, Graham and Jeffery Round. (1979) "Accounting and Fixed Price Multipliers in a Social Accounting Matrix Framework,” Economic Journal, 89, 850-873. . (1985) Social Accounting Matrices: A Basis for Planning, The World Bank, Washington, DC.

Pulido, Antonio and Emilio Fontela. (1993) Análisis Input-Output: Modelos, Datos y Aplicaciones. Pirámide.

Stone, Richard. (1978) "The Disaggregation of the Household Sector in the National Accounts," World Bank Conference on Social Accounting Methods in Development Planning, Cambridge, U.K.

Sosvilla, Simón, Oscar Bajo-Rubio, and Carmen Díaz-Roldán. (2006) "Assessing the Effectiveness of EU's Regional Policies: A New Approach," European Planning Studies, 14, 383-396.

Sharify, Nooraddin and Peter Batey. (2006) "Social Accounting and Regional Economic Planning: An Integrated Model for Policy Analysis and Optimization," Annals of Regional Science, 40, 639-660.

\section{APPENDIX}

TABLE A.1: Allocation rule for ERDF in Andalusia, 1989-1993 Annualized Community Support Framework (in millions of pesetas)

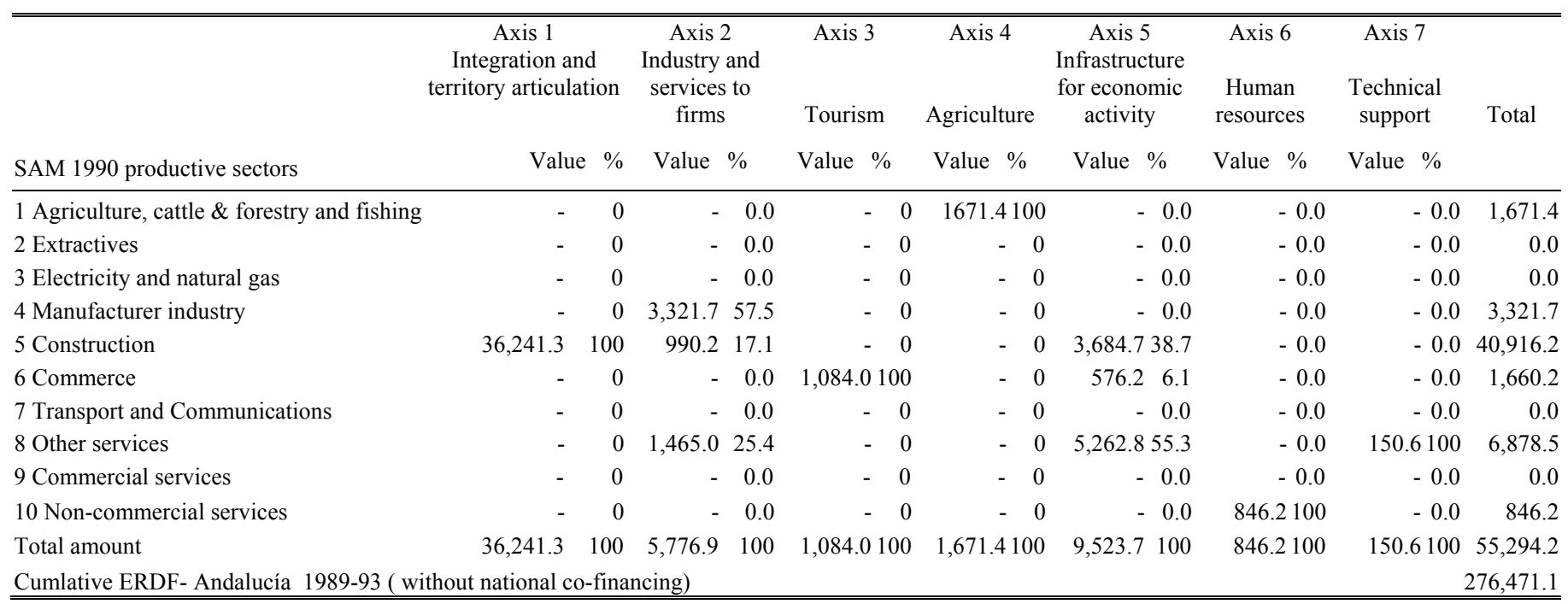

Source: Lima and Cardenete (2005). 
TABLE A.2: Allocation rule for ERDF in Andalusia, 1994-1999 Annualized Community Support Framework (in millions of pesetas)

\begin{tabular}{|c|c|c|c|c|c|c|c|c|c|c|c|c|c|c|}
\hline \multirow[b]{2}{*}{ SAM 1990 productive sectors } & \multicolumn{2}{|c|}{$\begin{array}{c}\text { Axis } 1 \\
\text { Integration and } \\
\text { territory } \\
\text { articulation }\end{array}$} & \multicolumn{2}{|c|}{$\begin{array}{c}\text { Axis } 2 \\
\text { Industry and } \\
\text { services to firms }\end{array}$} & \multicolumn{2}{|l|}{ Axis 3} & \multicolumn{2}{|c|}{ Axis 4} & \multicolumn{2}{|c|}{$\begin{array}{c}\text { Axis } 5 \\
\text { Infrastructure } \\
\text { for economic } \\
\text { activity }\end{array}$} & \multicolumn{2}{|c|}{$\begin{array}{c}\text { Axis } 6 \\
\\
\text { Human } \\
\text { resources }\end{array}$} & $\begin{array}{c}\text { Axis } 7 \\
\text { Technical } \\
\text { support }\end{array}$ & \multirow[t]{2}{*}{ Total } \\
\hline & Value & $\%$ & Value & e $\%$ & Value & $\%$ & Valu & $\%$ & Value & $\%$ & Value & $\%$ & Value $\%$ & \\
\hline 1 Agriculture, cattle \& forestry ar & - & 0 & - & 0 & - & 0 & 74.6 & 100 & - & 0 & - & 0 & -0 & $\overline{74.6}$ \\
\hline 2 Extractives & - & 0 & - & 0 & - & 0 & - & 0 & - & 0 & - & 0 & & 0.0 \\
\hline 3 Electricity and natural gas & - & 0 & - & 0 & - & 0 & - & 0 & - & 0 & - & 0 & & 0.0 \\
\hline 4 Manufacturer industry & - & 0 & $2,652.8$ & 57.5 & - & 0 & - & 0 & - & 0 & - & 0 & & $2,652.8$ \\
\hline 5 Construction & $42,663.6$ & 100 & 790.8 & 17.1 & - & 0 & - & 0 & $10,254.5$ & 38.7 & - & 0 & & $53,708.8$ \\
\hline 6 Commerce & - & 0 & - & 0 & $2,808.3$ & 100 & - & 0 & $1,603.5$ & 6.05 & - & 0 & & $4,411.8$ \\
\hline 7 Transport an & - & 0 & - & 0 & - & 0 & - & 0 & - & 0 & - & 0 & -0 & 0.0 \\
\hline 8 Other services & - & 0 & $1,170.0$ & 25.4 & - & 0 & - & 0 & $14,646.2$ & 55.3 & - & 0 & 361.3100 & $16,177.6$ \\
\hline 9 Commercial services & - & 0 & - & 0 & - & 0 & - & 0 & - & 0 & - & 0 & -0 & 0.0 \\
\hline 10 Non-commercial services & - & 0 & - & 0 & - & 0 & - & 0 & - & 0 & $4,473.6$ & 100 & -0 & $4,473.6$ \\
\hline Total amount & $42,663.6$ & 100 & $4,613.6$ & 100 & $2,808.3$ & 100 & 74.6 & 100 & $26,504.2$ & 100 & $4,473.6$ & 100 & 361.3100 & $81,499.2$ \\
\hline \multicolumn{5}{|c|}{ Cumulative ERDF-Andalucía 1994-1999 ( without national co-financing) } & & & & & & & & & & $488,995.1$ \\
\hline
\end{tabular}

Source: Lima and Cardenete (2005).

TABLE A.3: Allocation rule for ERDF in Andalusia, 2000-2006 Annualized Community Support Framework (in millions of pesetas)

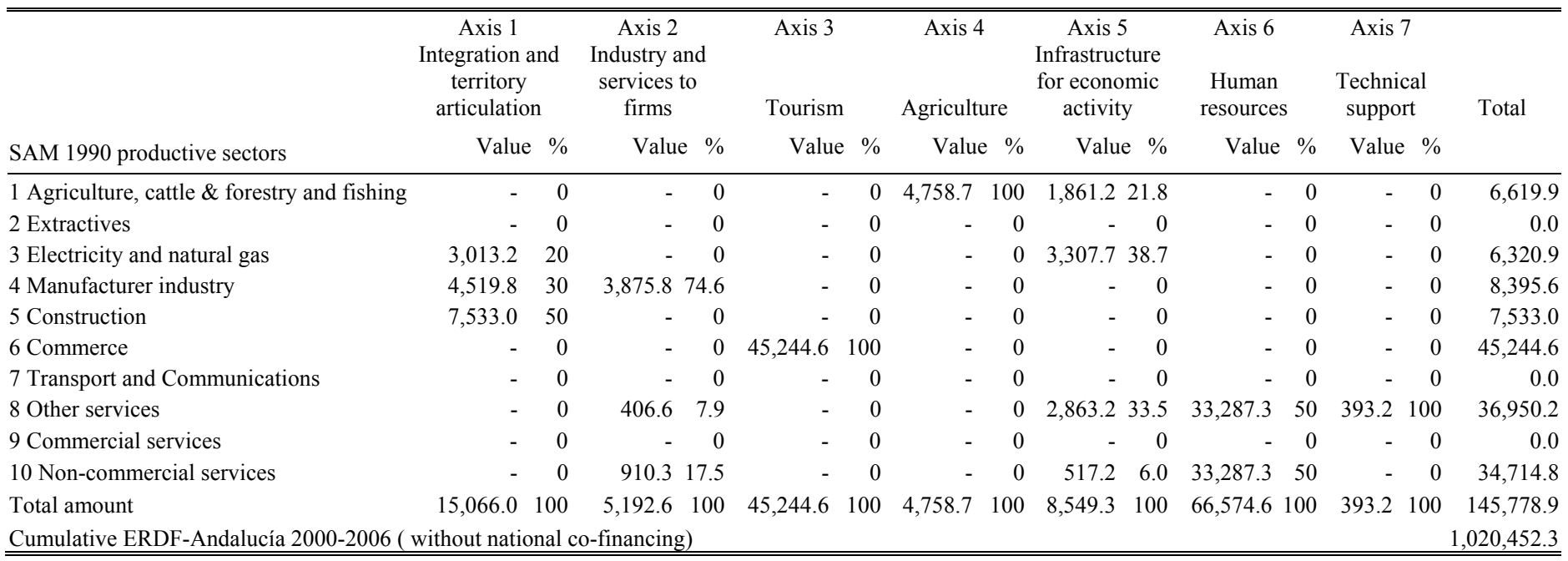

Source: Lima and Cardenete (2005). 